\title{
EDUCAÇÃO DO CAMPO: VIVÊNCIAS TRANSFORMADORAS NA REALIDADE LOCAL
}

\author{
Valentim da Silva ${ }^{1}$ \\ Vanessa Marion Andreoli ${ }^{2}$ \\ Michelle BocchiGonçalves ${ }^{3}$ \\ Gilson Walmor Dahmer ${ }^{4}$
}

\section{RESUMO}

Neste relato busca-se apresentar uma experiência pedagógica vivida em uma turma de Licenciatura em Educação do Campo - Ciências da Natureza, a partir da metodologia de Aprendizagem por projetos, proposta denominada "Rosa dos Ventos", em docência compartilhada. Os procedimentos metodológicos se deram em consonância com os princípios da Educação do campo, que almeja a construção de uma educação emancipatória por meio do reconhecimento crítico da realidade e da apropriação de conhecimentos necessários para ações pautadas na transformação social.

Palavras-chave: Educação do Campo; Aprendizagem por projetos; Docência compartilhada;

1 Doutor em Química pela Universidade Federal do Paraná - UFPR. Professor Adjunto, docente do Curso de Licenciatura em Ciências da UFPR Setor Litoral. E-mail valentimdasilva@gmail.com

2 Mestra em Sociologia pela Universidade Federal do Paraná - UFPR. Professora Assistente, docente do Curso de Licenciatura em Educação do Campo da UFPR Setor Litoral. E-mail: vanessaandreoli.ufpr@gmail.com

3 Mestra em Educação pela Universidade Federal do Paraná - UFPR. Professora Assistente, docente do Curso de Licenciatura em Educação do Campo da UFPR Setor Litoral. E-mail michellebocchi@gmail.com

4 Mestre em Agronomia pela Universidade Federal do Paraná - UFPR. Professor Assistente, docente do Curso de Licenciatura em Educação do Campo da UFPR Setor Litoral. E-mail gilsonwalmordahmer@hotmail.com

Criar Educação, Criciúma, v. 6, n², julho/novembro 2017.- PPGE UNESC 


\section{CRIAR EDUCAÇÃO \\ Revista do Programa de Pós-Graduação em Educação - UNESC

\section{ABSTRACT}

This report aims to present an educational experience that was lived in a class of LicenciaturaemEducação do Campo - Ciências da Natureza (Rural Educational Class - Natural Sciences), from a methodology called learning through projects, in shared teaching, which the proposal is named Rosa dos Ventos (Compass Rose).The methodological procedures were given in consonance with the principles of Educação do Campo (Rural Educational Class) which aims to build an emancipatory education through critical recognition of the reality and appropriation of necessary knowledge on actions based on social transformation.

Keywords:Rural Educational Class; Learning through projects; Shared teaching;

\section{Introdução}

Sendo o sujeito fruto de seu tempo histórico, das relações sociais em que está inserido, mas também, um ser singular, que atua no mundo a partir do modo que o compreende e como do mundo lhe é possível participar, buscouse, nesse sentido, proporcionar espaços transformadores da realidade local via processo de formação inicial no curso de Licenciatura em Educação do Campo: Ciências da Natureza, da Universidade Federal do Paraná, Setor Litoral. Essa abertura permitiu resgatar/instalar os saberes dos sujeitos (históricos culturais), como disparador inicial, para determinar o tipo de participação que lhes cabe como Educador do Campo. Entre os maiores desafios postos a licenciatura em questão, encontra-se, segundo Molina e Sá (2012).

[...] o de promover processos, metodologias e posturas docentes que permitam a necessária dialética entre educação e experiência, garantindo um equilíbrio entre rigor intelectual e valorização dos conhecimentos já produzidos pelos educandos em suas práticas educativas e em suas vivências socioculturais (p. 470).

Criar Educação, Criciúma, v. 6, n², julho/novembro 2017.- PPGE UNESC 
Nesse viés, o educador em formação que irá atuar nas escolas do campo, deve conhecer e respeitar as peculiaridades dos estudantes do campo, para que possa subsidiar o processo de desenvolvimento, de elaboração da identidade, da valorização da cultura camponesa, respeitando à trajetória de vida de cada indivíduo e a cultura local. Assim, encontra-se a necessidade de delinear um perfil de educador que, além de compreender as contradições sociais, ambientais e econômicas enfrentadas pelos sujeitos que vivem no campo, construa com as mesmas práticas didáticas pedagógicas que os instrumentalizem tanto para o enfrentamento quanto para superação dessas contradições (MOLINA e SÁ, 2012).

Partimos do entendimento que os saberes dos sujeitos são contemplados na abordagem do par ciência/senso comum, proposto por Santos (2005a), o qual define:

[...] dois tipos de conhecimento: ciência e senso comum. Embora opostos entre si, estas duas entidades epistémicas implicam-se reciprocamente, pois um não existe sem o outro. Com efeito, fazem parte da mesma constelação cultural que hoje em dia dá sinais de exaustão e extinção. Em suma, o senso comum é tão moderno quanto a própria ciência moderna (p. 107).

Desta forma entende-se que não há saber mais, ou saber mais importante, e que não deve-se imaginar o par ciência/senso comum, que constitui os saberes dos sujeitos, de forma isolada. Nem deve-se pensar que qualquer um deles é mais ou menos eficiente que o outro. Pelo contrário, estão ambos interligados e atuam em sinergia. Embora para alguns sujeitos, em determinado contexto, se utilize de um em preferência ao outro, o que supõem que está relacionado a inclinação da reflexão individual no coletivo. Mas, compreende-se que ambos fazem a gênese na constituição dos saberes dos sujeitos, e que, embora as linhas epistêmicas sejam convergentes, pode-se identificar o uso paralelo ou mesmo divergente na intencionalidade política, ao propor um conhecimento hierarquizado da ciência em relação aos saberes tradicionais dos sujeitos.

Criar Educação, Criciúma, v. 6, n², julho/novembro 2017.- PPGE UNESC 
Aqui, assumimos que ambos, saberes científicos e histórico-culturais são um só, são os saberes que constituem os sujeitos. Nesse sentido há necessidade da reinvenção nas proposições de construção dos saberes institucionais, especializados, enquanto um curso de Licenciatura em Educação do Campo integrado aos diferentes saberes históricos culturais das pessoas no contexto local.

Acredita-se que o combustível mobilizador para essa integração é a reflexão-ação-reflexão. Esse movimento contínuo, ao ser disparado, tenderá manter o movimento, sugerindo uma sequência orgânica de pesquisas, na perspectiva de auto identificar-se no contexto real com os diferentes instrumentos potencializadores, quer sejam ferramentas das instituições de ensino quer sejam das comunidades. $O$ fato é que para além do que se lê com palavras, busca-se ler com os olhos, com os sentidos, no mundo. Olhar o mundo atentamente, criticamente, para além das informações e dados postos e acabados. Que a reformulação, na proposição da construção dos saberes, estejam para além de um mundo imediatizado.

O que se propõe é a viabilização de encaminhamentos que potencializem a construção de saberes emancipatórios, no sentido de produzir conhecimento que enriqueçam nossas relações humanas no mundo com o mundo. Corroborando com Santos (2005a), buscamos construir os saberes na dimensão utópica e libertadora que pode valorizar-se, também, através do diálogo. Entendemos que os saberes prévios dos sujeitos se constituíram na sua trajetória de vida, frente às diferentes experiências. Experiência entendida no sentido proposto por Bondía que diz que

\footnotetext{
a experiência é o que nos passa, o que nos acontece, o que nos toca, e o sujeito da experiência é um território de passagem. [...] Somente o sujeito da experiência está, portanto, aberto à sua própria transformação. [...] O saber de experiência se dá na relação entre o conhecimento e a vida humana (2002).
}

Por esta via, pensar na formação de um educador do campo é pensar uma educação onde o indivíduo seja capaz de ser sujeito da experiência, privilegiando-se enquanto leitor das complexidades do cotidiano, pois pode 
colaborar na construção de ações emancipatórias, libertadoras, utópicas sem provocar rupturas separatistas e divisórias das estruturas sócio-culturais. E ainda, este cuidado está relacionado ao de não "atuar sobre os homens para, doutrinando-os, adaptá-los cada vez mais" (FREIRE, 1987).

Por esse motivo, os encaminhamentos didáticos pedagógicos, que entendemos que também são políticos e filosóficos, carregam em si o alerta antecipatório de não estabelecer uma visão de mundo sobre o mundo, que não seja o respeito ao tempo dos sujeitos, no seu tempo, no seu contexto sóciohistórico-cultural. É de extrema importância que ao pensarmos nessas atividades pedagógicas, vislumbremos projetos que sejam capazes de contemplar um olhar para os estudantes como sujeitos completos, concretos e contextualizados, partindo, como aponta Molina e Sá (2012, p. 472), de um "método para pensar em uma escola que integre o trabalho com o conhecimento aos aspectos mais significativos da vida real de seus sujeitos".

$E$, ainda, na intencionalidade freireana assume-se que

[...] a necessidade de atuar sobre a realidade social para transformála, ação que é interação, comunicação, diálogo. Educador e educando, os dois seres criadores libertam-se mutuamente para chegarem a ser, ambos, criadores de novas realidades. (FREIRE, 1979, p.08).

Para isso, os encaminhamentos para a construção do Educador do Campo, em sua natureza, tem forte caráter político freireano, o qual propõe utilizar o conjunto de saberes e ações dos sujeitos em relação a sua realidade e acredita na sua capacidade de transformá-la. Educação entendida, portanto, como prática social e política, visto que se afirma na proposição de valores que potencializam a transformação social, o pensamento crítico e a ação emancipatória.

Compreendendo que a educação para transformação social tem como ponto de partida a superação da realidade que vivenciamos, nos posicionamos esperançosos e não adeptos ao discurso acomodado (FREIRE, 1996, p.74) de que "não há o que fazer". Essa posição permite-nos refletir que a especificidade da formação do Educador do Campo reside no fato da 
promoção da consciência dos estudantes para compreensão, interpretação e transformação da realidade. Nessa linha de pensamento, cabe à escola uma responsabilidade específica de garantia da apropriação crítica e reflexiva dos saberes e elementos da cultura.

Assim, vislumbrar um projeto de formação desses profissionais, em que se percebam e atuem criticamente nas escolhas e premissas socialmente aceitas, nos quais sejam capazes de formular alternativas de um projeto político, atribui à escola do campo uma importante contribuição no processo mais amplo de transformação social. Além disso, a formação de educadores do campo, segundo Molina e Freitas (2011) é um desafio, pois a escola do campo deve conceber e desenvolver,

[ ] uma formação contra hegemônica, ou seja, de formular e executar um projeto de educação integrado a um projeto político de transformação social liderado pela classe trabalhadora, o que exige a formação integral dos trabalhadores do campo, no sentido de promover simultaneamente a transformação do mundo e a autotransformação humana (p. 24).

Nesse contexto, os docentes que atuam na formação de educadores do campo têm grandes desafios pela frente, entre eles o de encontrar alternativas metodológicas que, busquem instaurar um conjunto de princípios que embasem e orientem constantemente as práticas educativas que anunciam, "com a perspectiva de oportunizar a ligação da formação escolar à formação para uma postura na vida, na comunidade" (MOLINA e SÁ, 2012, p.329).

Nessa linha de pensamento apresentada, compartilhamos a experiência vivenciada por docentes e estudantes de uma das turmas do curso em questão, destacando que se torna crucial nesse processo percebermos o potencial transformador de metodologias que contemplem um novo olhar sobre a formação desses profissionais que venha ao encontro do projeto de escola do campo que almeja-se.

\section{Metodologia}

Criar Educação, Criciúma, v. 6, n², julho/novembro 2017.- PPGE UNESC 
As ações didáticas pedagógicas foram previamente planejada pelo coletivo de docentes no primeiro semestre e implementada no segundo semestre de 2015, no município de Cerro Azul-PR, no curso de Licenciatura em Educação do Campo: ciências da natureza do Setor Litoral da Universidade Federal do Paraná - UFPR.

Embasada nos princípios da Educação do Campo, propõem-se uma vivência em consonância com o Projeto Político Pedagógico do Setor Litoral da UFPR (PPP, 2008) e com o Projeto Político Pedagógico do Curso de Licenciatura em Educação do Campo (PPC LECAMPO, 2012).

O PPP da UFPR Litoral é voltado para o desenvolvimento social da região (Litoral do Paraná e Vale do Ribeira), tendo como principal fundamento o reconhecimento do local como ponto de partida e chegada na organização dos conteúdos a serem trabalhados durante o processo de construção do conhecimento pelos estudantes, que tem no educador a figura de mediador desse processo. Pode-se dizer que o conhecimento e problematização da realidade é a "fonte primeira" (PPP, 2008, p.6) que, em diálogo com o conhecimento sistematizado, permite o reconhecer-se e se reconhecer no local onde vive. Cumpre destacar que

\footnotetext{
[...] percebendo-se como uma instância de fomentos públicos, a UFPR Litoral alicerça seus compromissos com as regiões [...]. O foco desse apoio passa a se dirigir aos lugares onde os acordos de poderes públicos podem fazer diferença, se gestados em prol de uma educação universitária, pública e gratuita, com vistas a tecer e disponibilizar os produtos da ciência e do conhecimento especializado para um desenvolvimento sustentável. (PPP, 2008, p.2)
}

Nesse viés e na mesma perspectiva epistemológica insere-se como principal objetivo a possibilidade de formar estudantes a partir de propostas Freireanas, ou seja, no resgate do humano como sujeito de si e de sua própria educação, buscando a construção da autonomia e o comprometimento social dos sujeitos. Além disso, essa licenciatura considera as especificidades e a identidade dos povos do campo por meio de um processo educacional diferenciado, processo esse que seja capaz de vincular a prática pedagógica ao trabalho no campo, além de projetar outras formas de diversificação na

Criar Educação, Criciúma, v. 6, n², julho/novembro 2017.- PPGE UNESC 
propriedade, que potencializem o desenvolvimento de um projeto de vida na perspectiva de sustentabilidade - humana, ambiental e econômica.

Para promover essas intencionalidades, estabeleceu-se um cronograma de atividades que contemplava todos os encontros, porém não enrijecendo os encaminhamentos, de modo que a flexibilização contemplasse as proposições dos estudantes à realidade local.

Utilizou-se a metodologia de Aprendizagem por Projetos (KELLERFRANCO; MASETTO, 2012), docência compartilhada (CITOLIN, 2013), planejamento em coletivos de trabalho ${ }^{5}$ com alternância (Tempo Universidade e Tempo Comunidade ${ }^{6}$ ), itinerância e Avaliação Qualitativa (Demo, 2010). Esses encaminhamentos propiciaram acesso a maneiras diferenciadas de aprender. Especialmente aprender a aprender, partindo de vivências e problematizações vinculadas a realidade local, com discussões edificadas na práxis.

A docência compartilhada ocorreu por intermédio de quatro docentes de formações distintas nas áreas do conhecimento: Química, Biologia, Agroecologia e Pedagogia, que se disponibilizaram a compartilhar, planejar e dialogar juntos. No exercício efetivo, mediando a construção do perfil do educador do campo, provocados pelo diálogo de Paulo Freire com Marcio Campos em Pedagogia da Esperança (1992), Boa Ventura de Souza Santos em Universidade do Século XXI (2005) e A cor do Tempo Quando Foge (2014), confirmou-se a necessidade de desenvolvermos uma estratégia metodológica política pedagógica que viabilizasse as reflexões/ações, a qual denominou-se "Rosa dos ventos".

A metodologia "Rosa dos Ventos" suleou-nos ao longo dos encontros do semestre, no sentido Freireano, entendendo que elemento político expresso na palavra pode produzir sentidos que funcionam como mecanismos de reflexão e nos conduzem a assumir que o "Sul" (hemisfério) é capaz de produzir

5 A turma foi organizada em coletivos de trabalhos de acordo com interesses, afinidades e propostas dos projetos dos estudantes.

6 Entende-se por Tempo Universidade os períodos intensivos de formação presencial no local onde acontecem os encontros, e por Tempo Comunidade os períodos intensivos de formação presencial nas comunidades de origem dos estudantes.

Criar Educação, Criciúma, v. 6, n², julho/novembro 2017.- PPGE UNESC 
conhecimento. Ainda, as reflexões sobre a forma de produção de conhecimento, considerando os saberes pertinentes aos sujeitos e ao local, despertou-nos a atenção para o fato de que os nomes/conceitos (palavras geradoras) são carregados de sentidos (palavras grávidas).

Deste modo, estimulando os estudantes a perceberem a realidade criticamente, houve a necessidade de ressiginificar alguns conceitos de palavras e ainda se apropriar de conceitos que representasse o perfil do Educador do Campo. Assim, constituiu-se o Glossário de Educação do Campo da Turma, o qual originou os denominados "Operadores Conceituais", palavras conceitos que representam a realidade local e o sujeitos, e que foram tramados na então constituída "Dinâmica Trama Conceitual" do Curso de Licenciatura de Educação do Campo Cerro Azul.

$\mathrm{Na}$ turma, subdividida em cinco coletivos de trabalho, os estudantes construíram a "Rosas dos Ventos" que contemplassem a temática dos projetos, que tiveram como eixo temático as "Vivência transformadoras da realidade local" e a seguinte problemática: Quais são os conhecimentos técnicos que precisamos estudar que potencializam nosso projeto e nos proporcionam uma vivência transformadora na realidade local?

\section{RESULTADOS E DISCUSSÕES}

A busca constante de estratégias metodológicas que possibilitam a pesquisa-ação-reflexão, a partir de uma "[...] intencionalidade de educação do campo a favor da construção de uma nova concepção de campo, de reforma agrária e de agricultura familiar, e o papel do educador(a) neste processo" (PPC LECAMPO, 2012, p.7). Permitiu-nos identificar nesse processo um instrumento dos estudantes, e não somente dos docentes, os quais passam a identificar os conteúdos da aprendizagem com o processo mesmo de aprender e de ressignificar seu papel no reconhecer a sua realidade local.

$\mathrm{Na}$ busca de se abordar, como parte integrante do planejamento, a tarefa de definir e redefinir o processo de formação dos licenciados em

Criar Educação, Criciúma, v. 6, n², julho/novembro 2017.- PPGE UNESC 
Educação do Campo no fazer pedagógico em contexto com a realidade local e com os saberes dos sujeitos pode identificar o cuidado no trato entre os envolvidos. E nesses movimentos, percebidos também pelos estudantes, evidenciou esse afeto coletivo, esse compromisso com o outro, com aquele que também é responsável pela 'minha' aprendizagem. Esses movimentos proporcionaram identificar a vivência defendida por Freire (1979, p.39), quando afirma que "ninguém educa ninguém, ninguém educa a si mesmo, os homens se educam entre si, mediatizados pelo mundo".

É importante acentuar que os processos participativos possibilitaram a efetiva participação, em sentido mais denso, pois exigiu a leitura de mundo no tempo de convivência e no compromisso coletivo. Assumiu-se que planejar não é um ato neutro. Esta atividade, historicamente situada, serve tanto para manutenção do status quo quanto para mudança. O educador do campo é uma das pessoas responsáveis pela organização do trabalho educativo no âmbito da sala de aula, da escola e do seu entorno. Com efeito, o planejamento se apresentou como espaço em que exerceu seu poder de intervenção sobre os contornos e rumos do fazer pedagógico e didático. Tal atuação se concretizou por meio de sua participação no delineamento, atualização e revisão do planejamento de ensino e de sua ação didática propriamente dita através de projetos de intervenção na realidade local. Ainda, pode-se confirmar que a identidade do professor é um lugar de luta e de conflito, construção e desconstrução, de maneiras de ser e estar na profissão professor.

Constatou-se que é possível, na perspectiva político filosófica que aponta o PPC da Licenciatura de Educação do Campo (PPC LECAMPO, 2012), a qual está pautada na superação da divisão social do trabalho, ou seja, de uma prática hierarquizada, onde alguns pensam e outros executam, construir ações que transformem a realidade local, à partir de projetos propostos pelos estudantes e mediados pelos docentes.

Afirmamos que a proposta, além de atender o planejamento para a construção do profissional licenciado em educação do campo, também buscou proporcionar espaços de vivências transformadoras da realidade local, da 
escola e do seu entorno (comunidade), integrado ao aprofundamento de conhecimentos específicos da área.

Diante dos desafios encontrados no semestre, referente as alternativas e encaminhamentos metodológicos, didáticos e pedagógicos considerou-se suficiente no sentido do empoderamento, embasando-se nos apontamenso de Bondía (2002) no que diz respeito a: Qualidade Formal, a qual compreende a versatilidade dos meios, de estilo metodológico, processual, científico, com base no manejo e construção do conhecimento; e da Qualidade Política, que compreende a intensidade democrática e ética frente aos desafios dos fins e valores sociais. Acreditando que a premissa é uma concepção epistemológica fundada na educação emancipatória, os encaminhamentos contemplaram os sujeitos envolvidos no processo, que se "alimentavam" na realidade local.

O desenvolvimento das atividades, em docência compartilhada, possibilitou-nos a mediação na perspectiva dialética, no envolver-se num fazer pedagógico participativo, planejado coletivamente, com diálogos e trocas de ideias, nos auxiliando na restruturação da nossa postura enquanto docentes e ao mesmo tempo a aprender no exercício educador com os colegas e estudantes o prenúncio freireano "nos educamos uns aos outros".

\section{CONCLUSÕES}

Considerando que a Educação do campo compreende tanto os processos culturais, quanto as estratégias de socialização e as relações de trabalho vividas pelos sujeitos do campo em suas lutas cotidianas como elementos essenciais de seu processo formativo, entendemos que as proposições e encaminhamentos que buscaram auxiliar na construção do perfil do educador do campo possibilitaram-nos propor e construir fundamentos epistemológicos para sua constituição enquanto tal, relacionando as formulações, apropriação e ressignificação dos conceitos histórico-sociológicos transformando-se em uma aprendizagem contextualizada.

Ainda, os trabalhos colaborativos a partir do envolvimento com a realidade local, com as escolas, comunidades e seu entorno, integrando-se aos

Criar Educação, Criciúma, v. 6, n², julho/novembro 2017.- PPGE UNESC 
estudos e análises de metodologias de aprendizagem, mudanças conceituais, aprendizagem significativa, que através dos registros nos possibilitaram a construção de materiais didáticos como o Glossário Lecampo, a Dinâmica Trama Conceitual, os Operadores Conceituais, que se integraram e nos potencializaram na nossa leitura crítica de mundo.

Ainda, evidenciamos que a formação ocorre diretamente com a realidade, mediada pela busca de ações e reflexões, de intervenção, no movimento: conhecer e compreender; compreender e identificar-se; identificarse e propor; propor e agir.

Também foi importante observar que compartilhar a docência foi uma ideia inovadora e instigante, pois apesar de beneficiar diferentes estilos de ensino, da colaboração entre profissionais de diferentes áreas de formação e da utilização de alternativas de ensino por parte de cada docente e de cada estudante em formação, necessita ainda de uma mobilização para sair da individualidade e alcançar a concepção de identidade coletiva. A docência Compartilhada, portanto, passa por esta identidade coletiva, que é trilhar um objetivo comum, onde os envolvidos sejam capazes de compartilhar anseios que se encontram, incompletudes que se completam, inseguranças que são superadas e saberes que se asseguram.

É de suma importância destacar que a educação possibilita a transformação das realidades das escolas e das comunidades dos estudantes, quando os sujeitos "instrumentalizados" que fazem parte do processo criam condições reais para a prática social transformadora, embasados pela crítica aos elementos culturais disseminados pelos currículos tradicionais.

Para finalizar, reafirmamos que quando pensamos em metodologias alternativas que contemplem os sujeitos e suas realidades, é crucial compreendermos que a aprendizagem se dá a partir das experiências particulares que temos, pois essas são envoltas de afetividade, emoção, sentimento e esses elementos vão moldando nossa percepção sobre o mundo, sobre os outros e, mais do que isso, embasam nossas ações. Sendo assim, aprendemos a partir do local onde vivemos, experimentando, reorganizando, tentando melhorar, e elaborando perguntas para dar respostas imediatas aos

Criar Educação, Criciúma, v. 6, n², julho/novembro 2017.- PPGE UNESC 
problemas encontrados no dia a dia. A reflexão, quando mediada por outros sujeitos, como é o caso da escola, dialoga com essa bagagem de saberes que os estudantes trazem e permite que, a partir deles, se organize os saberes escolares e construa novas visões e ações no mundo.

\section{REFERÊNCIA}

BONDÍA, Jorge Larrosa. Notas sobre a experiência e o saber de Experiência. Tradução de João Wanderley Geraldi. Campinas, SP: Leituras SME.Jan/Fev/Mar/Abr, 2002, No 19, p. 20-28.

CALDART, R.S.; PEREIRA, I.B.; ALENTEJANO, P.; FRIGOTTO, G.Dicionário da Educação do Campo. $2^{a}$ Ed. Rio de Janeiro, São Paulo: Escola Politécnica de Saúde Joaquim Venâncio, Expressão Popular, 2012.

CITOLIN, C.H. Eu falo, tu hablas, vos hablás, nós ensinamos e aprendemos juntos: aulas de línguas em cursos binacionais.Tese (Doutorado) - Pós-Graduação em Educação da Universidade do Vale do Rio dos Sinos - UNISINOS.São Leopoldo-RS, 2013.

DEMO, Pedro. Avaliação qualitativa. $10^{\mathrm{a}}$ Ed. Campinas, SP: Autores Associados - Coleção polêmicas do nosso tempo; 2010.

FREIRE, Paulo. Pedagogia do Oprimido. $17^{\mathrm{a}}$ Ed., Rio de Janeiro: Paz e Terra, 1987.

. Conscientização: teoria e prática da libertação: uma introdução ao pensamento de Paulo Freire. São Paulo: Cortez \& Moraes, 1979. Pedagogia da Esperança: Um reencontro com a Pedagogia do Oprimido. Notas: Ana Maria Araújo Freire, Rio de Janeiro: Paz e Terra,1992. 


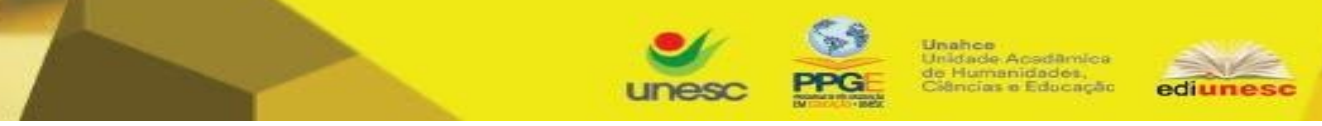

- Pedagogia da autonomia: saberes necessários à prática educativa. Coleção Leitura - São Paulo: Paz e Terra, 1996.

KELLER-FRANCO, Elize; MASETTO, Marcos Tarciso. Currículo por projetos no ensino superior: desdobramentos para a inovação e qualidade na docência.Uberaba: Revista Triangulo, jul./dez. 2012, v. 5, n. 2, p. 03-21.

MOLINA, C.M.; SÁ, L.M.. Licenciatura em Educação do Campo. In: CALDART, R.S.;

PEREIRA, I.B.; ALENTEJANO, P.; FRIGOTTO, G.Dicionário da Educação do Campo. $2^{\text {a }}$ Ed. Rio de Janeiro, São Paulo: Escola Politécnica de Saúde Joaquim Venâncio, Expressão Popular, 2012. p.466-472.

PPC-LECAMPO.Projeto Pedagógico De Curso Licenciatura Em Educação do Campo. Universidade Federal do Paraná: Setor Litoral. 2013. Disponível em http://www.litoral.ufpr.br. Acesso em: 24 Março 2016.

PPP. Projeto Político Pedagógico. Universidade Federal do Paraná: Setor Litoral. 2008. Disponível em http://www.litoral.ufpr.br/ppp. Acesso em: 09 Maio 2016.

SANTOS, Boaventura de Souza. A Cor do Tempo Quando Foge: uma história do presente. Crônicas 1986-2013. São Paulo: Cortez. 2014.

A crítica da razão indolente: contra o desperdício da experiência. IN Para um novo senso comum: A ciência, o direito e a política na transição paradigmática. $5^{\text {a }}$ Ed. São Paulo: Cortez. 2005a.

A Universidade do XXI: para uma reforma democrática e emancipatória da universidade. $2^{\mathrm{a}}$ Ed. São Paulo: Cortez. (Coleção questões da nossa época; v. 120), 2005b.

Criar Educação, Criciúma, v. 6, n², julho/novembro 2017.- PPGE UNESC 
STRECK, Danilo R.; REDIN, Euclides; ZITKOSKI, Jaime José; (orgs.).Dicionário Paulo Freire. $2^{\mathrm{a}}$ Ed. Belo Horizonte: Autêntica Editora, 2010. 